\title{
Pingers cause temporary habitat displacement in the harbour porpoise Phocoena phocoena
}

\author{
Line A. Kyhn ${ }^{1, *}$, Poul B. Jørgensen ${ }^{1,3}$, Jacob Carstensen ${ }^{1}$, Nikolaj I. Bech ${ }^{1,4}$, \\ Jakob Tougaard ${ }^{1}$, Torben Dabelsteen ${ }^{2}$, Jonas Teilmann ${ }^{1}$ \\ ${ }^{1}$ Department of Bioscience, Aarhus University, Frederiksborgvej 399, 4000 Roskilde, Denmark \\ ${ }^{2}$ Section for Ecology \& Evolution, Department of Biology, University of Copenhagen, Universitetsparken 15, \\ 2100 Copenhagen Ø, Denmark \\ ${ }^{3}$ Present address: Knuthenborg Safaripark, Knuthenborg Alle, 4930 Maribo, Denmark \\ ${ }^{4}$ Present address: Danish Technological Institute, Gregersensvej 1, 2630 Taastrup, Denmark
}

\begin{abstract}
Several studies have shown that pingers mitigate porpoise bycatch and thus pinger use is now mandatory in some fisheries-although the long-term effects of pinger exposure on porpoises have not been well studied. The effects of 2 types of pingers (Airmar: $10 \mathrm{kHz}$ tone; SaveWave Black Saver: 30-160 kHz sweep) on the presence of wild harbour porpoises, Phocoena phocoena, were investigated in 2 areas. Pinger spacing within the areas was similar to that used in commercial fisheries. Two scenarios were tested: (1) pingers were periodically activated and deactivated during 6 periods resembling the deployment and recovery of nets in a gillnet fishery, and (2) pingers were active continuously for $28 \mathrm{~d}$. Acoustic dataloggers (T-PODs) were deployed, 4 within the pinger areas and 3 in control areas, and detected porpoise echolocation activity throughout the entire study. During the periodic-exposure scenario, the porpoise detection rate was reduced by $56 \%$ when pingers were active. The reduction was larger for the SaveWave pingers (65\%) than for the Airmar pingers $(40 \%)$. There was a tendency for the encounter rate to increase after the first 2-4 periodic exposures, which could indicate gradual habituation. During the continuous-exposure scenario, the detection rate was reduced by $65 \%$ throughout the $28 \mathrm{~d}$ with no sign of habituation. In the control areas (2.5, 3 and $5 \mathrm{~km}$ distant), neither a decrease nor an increase in detection rate was observed, suggesting that porpoises were displaced either $<2.5 \mathrm{~km}$ or $>5 \mathrm{~km}$ away. If pingers are used as deterrent devices, the impact of habitat exclusion must therefore be considered concurrently with mitigation of bycatch, especially when regulating fisheries in Marine Protected Areas.
\end{abstract}

KEY WORDS: Acoustic deterrent devices - ADD - Small odontocetes - Habituation - Habitat displacement - Bycatch - T-POD - Passive acoustic monitoring - Special Areas of Conservation · Noise pollution

Resale or republication not permitted without written consent of the publisher

\section{INTRODUCTION}

Throughout its range, the harbour porpoise Phocoena phocoena (L., 1758) faces the threat of entanglement in gill nets (e.g. IWC 1994, Read 1994, Vinther 1999, Northridge et al. 2003). So far, the most promising tools to reduce porpoise bycatch are acoustic deterrent devices (ADD), so-called 'pingers', which emit sounds and are mounted on the head rope of gillnets. Since the development of the first prototype
(Lien et al. 1992), many experiments with pingers have been conducted. Behavioral studies with porpoises both in captivity (Kastelein et al. 2001, Teilmann et al. 2006) and in the wild (Cox et al. 2001, Koschinski et al. 2006, Larsen \& Krog 2007, Carlstrøm et al. 2009, Hardy et al. 2012) have shown that pingers and pinger-like signals deter porpoises. Moreover, double blind trials conducted in fisheries have shown that pingers reduce porpoise bycatch significantly (Kraus et al. 1997, Trippel et al. 1999, Larsen et 
al. 2002) (see Dawson et al. 2013 for a full list of pinger trials and studies). Based on the $92 \%$ reduction in the bycatch rate found by Kraus et al. (1997), use of pingers, together with time/area exclusion of fishery and gear modification, was mandated in USA legislation (Harbor Porpoise Take Reduction Plan, www.greateratlantic.fisheries.noaa.gov/protected/ porptrp/). However, control hauls undertaken in the fishery found only a 50 to $70 \%$ reduction in nets with pingers compared to nets without pingers (Palka et al. 2008). Those authors concluded that the reduced effect was partially caused by the incorrect use of the pingers and by the use of a different mesh-size than that used in Kraus et al. (1997).

In 2004, the Council of the European Union laid down measures concerning incidental catches of cetaceans in European fisheries (EU 2004). The use of pingers was mandated in gill net fisheries over a wide range of the North and Baltic Seas, with full implementation in 2007. However, several essential questions concerning the reactions of porpoises to prolonged pinger exposure remain unanswered. Firstly, the central question is whether a displacement effect caused by pingers may lead to habitat exclusion and, as a consequence, have a larger impact on the survival of porpoise populations than bycatch itself. Secondly, it is important to determine if - and if so, to what extent - porpoises may habituate to or gain useful information from pinger sounds when recurrently exposed to them, i.e. the porpoises may temporarily habituate to the pingers if they, as a consequence of avoiding nets, are not caught. Both Cox et al. (2001) and Carlstrøm et al. (2009) found significant signs of habituation to single pingers in experimental setups without nets, which may not be surprising given the lack of negative reinforcement from the presence of fishing nets. Real fisheries may provide such negative reinforcement and may explain why the results of pinger trials in fisheries do not show increases in bycatch rates over time (Kraus et al. 1997, Trippel et al. 1999, Larsen et al. 2002). As legislation mandates pingers to be placed at intervals of a few hundred meters (depending on pinger type) along the gill net chains (EU 2004), a large number of pingers are used within areas of high gillnet fishery activity. Furthermore, each net deployment may last from a few hours to a few days, which makes the use of pingers in the real fishery very different from previous experimental designs with a single or a few pingers.

The main purpose of this study was to investigate how porpoises would react to long-term exposure to a large number of pingers. Would the porpoises remain in the exposed area, and if not, would they return to the area after removal of the pingers? Two scenarios were tested: (1) a simulation of the type of exposure experienced in a gillnet fishery in which pingers were deployed and recovered in repeating cycles and (2) a test in which the pingers were continuously active for a longer period (several weeks). Porpoise presence was evaluated using passive acoustic dataloggers (T-PODs).

\section{MATERIALS AND METHODS}

\section{Experimental set-up}

The experiment was conducted from April to November 2005 in Jammerland Bay in the Great Belt, Denmark $\left(55^{\circ} 35^{\prime} \mathrm{N}, 11^{\circ} 5^{\prime} \mathrm{E}\right)$. This area was chosen for its high porpoise density (Teilmann 2003), limited depth (10 m maximum) and limited fishing and recreational sailing activity. On April 15, 7 passive acoustic porpoise detectors (T-PODs, Chelonia) were deployed at 4 different locations: 2 T-PODs were positioned $600 \mathrm{~m}$ apart in a northern impact area (Impact NE and Impact NW), 2 T-PODs were positioned $600 \mathrm{~m}$ apart in a southern impact area (Impact SE and Impact SW) and 3 T-PODs were positioned at control sites (Control N: $5 \mathrm{~km}$ north of the northern impact area; Control S: $3 \mathrm{~km}$ south of the southern impact area; Control E: between the 2 impact areas, $2.5 \mathrm{~km}$ from the nearest pinger) (Fig. 1). The T-PODs were placed between 1.3 and $2.3 \mathrm{~km}$ from the shore at $\sim 7 \mathrm{~m}$ depth above moraine/muddy sand bottom. They were deployed continuously from April 15 to November 8 and were not interchanged between locations (following the method of Carstensen et al. 2006). Data from the T-PODs were downloaded every $4^{\text {th }}$ week, batteries $(6 \times 1.5 \mathrm{~V}$ lithium D-cell $)$ were replaced and barnacles and mussels were removed from the T-PODs and moorings.

The study was conducted according to the following schedule:

(1) Baseline (April 15 to May 13): only the T-PODs were in the water, and this period served as the baseline.

(2) Periodic exposure (May 13 to June 29): the pingers were activated and deactivated cyclically with on and off periods of between 2 and $9 d$, dependent on the weather.

(3) Recovery 1 (June 29 to August 8): no pingers were active (they were physically removed from the buoys).

(4) Continuous exposure (August 8 to September 5): the pingers were continuously active. 


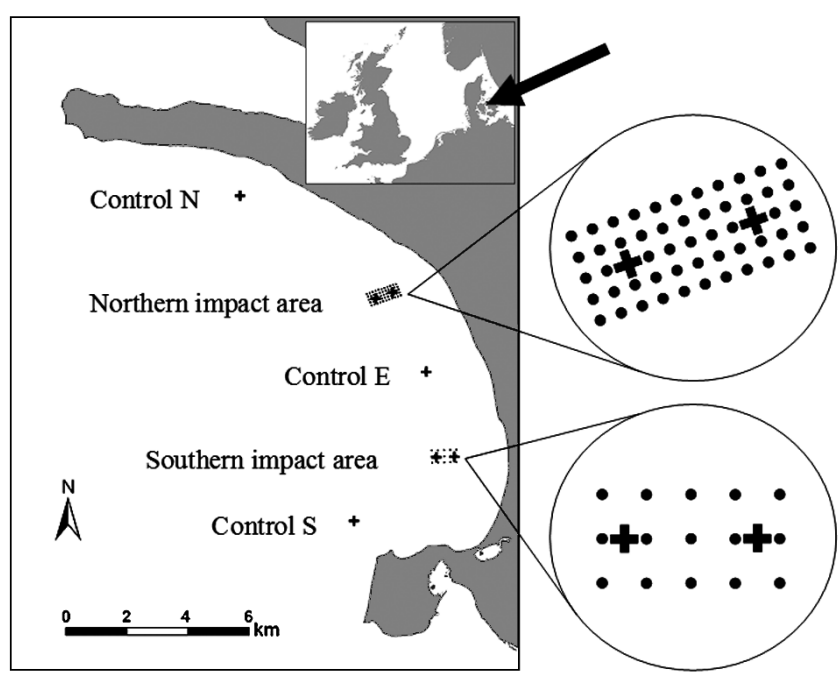

Fig. 1. Experimental setup in Jammerland Bay, the Great Belt, Denmark. Pingers (circles) were spaced 100 m (Northern impact area; Airmar pingers) and $200 \mathrm{~m}$ (Southern impact area; SaveWave pingers) apart. The 2 T-PODs (crosses) within each impact area were spaced $600 \mathrm{~m}$ apart

(5) Recovery 2+3 (September 5 to November 8): the pingers were removed. This period was split into two subperiods before (Recovery 2) and after (Recovery 3) October 6.

Airmar ( $\mathrm{n}=55$; Airmar Technology Corporation) and SaveWave Black Saver ( $\mathrm{n}=15$; SaveWave BV) pingers were deployed in the northern and southern impact areas, respectively. All pingers were attached $\sim 0.5 \mathrm{~m}$ below the surface at the end of $2 \mathrm{~m}$ long ordinary fishing buoys (Tonkin cane with styrofoam float and lead weight), which were held in place with $6 \mathrm{~mm}$ nylon rope tied to an anchor. The buoys with pingers were spaced $100 \mathrm{~m}$ (Airmar) and $200 \mathrm{~m}$ (SaveWave) apart for the northern and southern areas, respectively, in agreement with the range and maximum allowed spacing for the 2 pinger types (EU 2004). This setup possibly represents the 'worst case' scenario given that in the fisheries most nets are likely spaced more widely. Thus, an area of $\sim 0.6 \mathrm{~km}^{2}$ was covered by the pingers in each impact area. All pingers and batteries were new at the time of deployment and were active for about $1400 \mathrm{~h}$ during the study. This is well within the battery life given by the pinger manufacturers: $1 \mathrm{yr}(8800 \mathrm{~h})$ of continuous operation for the Airmar pingers and $2000 \mathrm{~h}$ of continuous operation for the SaveWave pingers. Nevertheless, the batteries of the Airmar pingers were replaced after the Periodic exposure schedule, while the sealed electronics compartment of the SaveWave pingers did not enable battery replacement.

\section{T-PODs}

All 7 T-PODs were the new version 3 type (Chelonia; see Kyhn et al. [2008] for a technical description of the T-POD). All T-PODs had identical settings: Target A filter frequency $=130 \mathrm{kHz}$; Reference $\mathrm{B}$ filter frequency $=90 \mathrm{kHz}$; Selectivity ratio $\mathrm{A} / \mathrm{B}=5$; 'A' filter integration time $=$ Short; ${ }^{~} \mathrm{~B}$ ' filter integration time $=$ Long; Minimum intensity $=6$; Scan limit $=$ 240 clicks; Minimum click duration $=30 \mu \mathrm{s}$. All T-PODs were tested and calibrated in a tank and in the field prior to the study in accordance with Kyhn et al. (2008). Maximum detection range for these T-PODs was about $450 \mathrm{~m}$ (Kyhn et al. 2012).

After download, clicks were processed through a classification filter (T-POD.exe ver. 7.41) supplied by the manufacturer. The CET ALL filter setting was used, which retains only the 2 train classes most likely to contain true porpoise clicks (Cet $\mathrm{Hi}$ and Cet Low). The detection algorithm remains undocumented but classification is based primarily on variation in inter-click intervals within closely spaced groups of clicks (trains).

\section{Pingers}

The Airmar pinger emitted a $300 \mathrm{~ms}$ signal at $10 \mathrm{kHz}$ with a nominal source sound pressure level of $132 \mathrm{~dB}$ re $1 \mu \mathrm{Pa}$ (rms). The signal was emitted once every $4 \mathrm{~s}$. The SaveWave Black Saver pinger emitted frequency modulated sweeps with signal parameters varying randomly within fixed limits. These signals were multiharmonic up-sweeps in the range 30$160 \mathrm{kHz}$ with durations from 200 to $900 \mathrm{~ms}$. Nominal source sound pressure level was $155 \mathrm{~dB}$ re $1 \mu \mathrm{Pa}$ (rms). Sweeps were emitted every 4 to $16 \mathrm{~s}$. Specifications of the 2 pingers correspond to the Type 1 and Type 2 pinger, respectively, of the European Union pinger directive (EU 2004) and are comparable to the Dukane NetMark 1000 and the PICE pinger, respectively, that have been used in most other pinger studies. Previous studies have found substantial variation in source level both among and within pinger types (Dawson et al. 2013). We measured sound pressure level from both Airmar and SaveWave pingers at distances ranging from $5 \mathrm{~m}$ to $1.6 \mathrm{~km}$ with a Reson TC4032 hydrophone connected to a Wavebook 512 (500 kHz sampling rate, 12 bit resolution). Recordings were made at seastate 2 Beaufort from one of the corners of each pinger site. One of the Airmar pingers was tested in a tank by Shapiro et al. (2009), who found that at range $=1 \mathrm{~m}$ there was up to $4 \mathrm{~dB}$ differ- 
ence in the source level depending on the recording aspect. At range $=100 \mathrm{~m}$ in the field there was up to $10 \mathrm{~dB}$ variation in source energy level, but at ranges $>100 \mathrm{~m}$ the back-calculated source level matched the manufacturer specifications. The difference in received level may be due to the propagation conditions at the study site and/or the reception of signals from multiple pinger units, as the recordings were made from the corner of the pinger site. The SaveWave pinger was only measured in the field and the recordings were made from the corner of the pinger site and therefore include several pinger units. However, the back-calculated source level from the field recordings confirmed the specifications stated by the manufacturer (see Fig. 5 and Shapiro et al. 2009).

\section{Statistical analysis}

T-PODs detect and store the time and duration of likely porpoise echolocation clicks. The T-POD porpoise detections were analysed as so called 'encounters' (Carlstrøm 2005, Carstensen et al. 2006) and a porpoise encounter was accordingly defined as a period with echolocation clicks separated by a silent period of at least $10 \mathrm{~min}$. From here on they are termed 'acoustic encounters'. The daily porpoise acoustic encounter rate was calculated as the observed number of acoustic encounters divided by the period that the T-POD was actively recording. Due to loss of data from some T-POD deployments, the data set was not completely balanced.

Two questions were addressed using the T-POD data. (1) Was there a significant change in daily encounter rate during periods with active pingers compared to periods with inactive pingers and if so, was the change similar for the 2 pinger types? (2) Did the effect of pingers on the daily encounter rate diminish over time, suggesting that porpoises habituated to the signals? These questions were addressed with 2 models described in the next paragraph. First, a model of general pinger effect was used on the entire study period, and second, the effect of individual periods of pinger exposure was tested using the Baseline, Periodic exposure schedule and Recovery 1 periods.

In the first model, changes in porpoise encounters in the impact area relative to the control area were investigated by extending the BACI design (BeforeAfter-Control-Impact; Green 1979) to include 6 periods as opposed to the normal 2. The BACI design can be viewed as a variant of the split-plot design (used when there is a restricted randomisation, here because the pingers were activated and deactivated at the same time in all areas; see Carstensen et al. 2006), with each day considered as a separate plot since the 6 levels of treatment (periods) were not monitored consistently at all T-PODs. Daily encounter rates $(X)$ were log-transformed after adding 1 to account for zero observations, i.e. $Y=\log (X+1)$, and analysed as normal variants with a mixed model (full model specified):

$$
\begin{aligned}
Y_{i j k l m}= & \mu+\underbrace{D_{i}+p_{j}+D P_{i j}}_{\text {whole-plot }}+\underbrace{a_{k}+D A_{i k}+p a_{j k}+D P A_{i j k}}_{\text {split-plot }} \\
& +\underbrace{s_{l(k)}+D S_{i l(k)}+p s_{j l(k)}+D P S_{i j l(k)}}_{\text {split-plot(subarea) }} \\
& +\underbrace{T_{m(k l)}+D T_{i m(k l)}+P T_{j m(k l)}+D P T_{i j m(k l)}}_{\text {split-plot(t-pod) }}+\varepsilon_{i j k l m}
\end{aligned}
$$

where $\mu$ is the overall mean, and effects are given by their first letter: $a_{k}$ for variation between areas (2 levels: $k=$ control, impact); $p_{j}$ for variation between periods (6 levels: $j=$ Baseline, Periodic exposure, Recovery 1, Constant exposure, Recovery 2, Recovery 3); $S_{l(k)}$ for variation between subareas nested within the 2 main areas (5 levels: $1=$ Control N, E, and S, and Impact $\mathrm{N}$ and $\mathrm{S}$ ); and $T_{m(k l)}$ for variation between T-PODs nested within subareas ( 7 levels: $m=$ individual T-PODs). There were $175 \mathrm{~d}$ in the design, denoted by $D_{i}$ (different days indexed by $i$ ). In Eq. (1), interactions between these effects are given by their letter combination and subscripts are indices for different levels of the effects in the model, with nesting indicated by parentheses. The model in Eq. (1) has 5 fixed effects (indicated by lowercase letters): $p_{j}$ (period) describes the different treatments; $a_{k}$ (area) describes the spatial variation between control areas on one hand and impact areas on the other; $p a_{j k}$ describes the relative change between control and impact areas among periods; $S_{l(k)}$ (subarea(area)) describes the differences between Control N, E, and S, and Impact $\mathrm{N}$ and $\mathrm{S}$, respectively; and $p s_{j l(k)}($ subarea(area) $\times$ period) describes the relative changes between periods within areas. The random effects of the model are indicated by uppercase letters: $T_{m(k l)}$ (t-pod(area $\times$ subarea)) describes the variation between the T-PODs deployed within Impact $\mathrm{N}$ and $\mathrm{S}$ (those subareas with multiple T-PODs); $D_{i}$ (day) describes the temporal variation across the study period; and 8 interactions. The significance of the random effects was tested and non-significant random effects were pooled with the residual variation by backward elimination. The residuals from the resulting model were examined to verify the distributional assumptions.

In the second model, differences between individual Periodic exposures on the encounter rate 
were investigated by analysing the first 3 periods with a modification of Eq. (1). As opposed to Eq. (1), where the objective was to investigate differences between periods, the state of the pingers was a main effect with individual Periodic exposures and intermediate periods as a nested effect of this. Thus, the log-transformed encounter rates were analysed as:

$$
\begin{aligned}
& Y_{i j k l m n}=\mu+\underbrace{D_{i}+o_{j}+D O_{i j}+p_{k(j)}+D P_{k(i j)}}_{\text {whole-plot }} \\
& +\underbrace{a_{1}+D A_{i l}+o a_{j l}+D O A_{i j l}+p a_{k l(j)}+D P A_{i k l(j)}}_{\text {split-plot }} \\
& +\underbrace{s_{m(l)}+D S_{i m(l)}+o S_{j m(l)}+D O S_{i j m(l)}+p s_{k m(j l)}+D P S_{i k m(j l)}}_{\text {split-plot(subarea) }} \\
& +\underbrace{T_{n(m l)}+D T_{i n(m l)}+O T_{j n(m l)}+D O T_{i j n(m l)}+P T_{k n(j l m)}+D P T_{i k n(j l m)}}_{\text {split-plot(t-pod) }}+\varepsilon_{i j k l m n}
\end{aligned}
$$

where the modifications to Eq. (1) were that $o_{j}=$ pinger status (2 levels: $j=\mathrm{ON}$ or OFF); and $p_{k(j)}=$ period (6 levels for $j=$ ON [6 Periodic exposures], 7 levels for $j=$ OFF [baseline and 6 periods following the Periodic exposures]). There were 15 random effects in the model in addition to the fixed effects, and non-significant random effects were pooled with the residual variation by backward elimination. The residuals from the resulting model were examined to verify the distributional assumptions.

Marginal means for the different factors of the models were calculated and back-transformed to mean values on the original scale using the moment's transformation of the log-transform (McCullagh \& Nelder 1989, p. 285) and subtracting 1 min. The interaction $p a_{j k}$ in Eq. (1) described whether there were significant shifts in the daily encounter rate between the impact and control areas during the 5 periods. In order to investigate the relative changes between 2 periods only, contrasts from the model estimates, similar to the original BACI design (2 periods: before and after), were computed using the 4 marginal means from combinations of the 2 areas and 2 selected periods, e.g. relative change between areas from the Periodic exposures to the Recovery 1. Contrasts were computed similarly for Eq. (2) to investigate different combinations of factor levels.

The statistical analyses were carried out within the framework of mixed linear models (Littell et al. 1996, McCulloch \& Searle 2001) by means of PROC MIXED in the SAS system. Statistical testing for fixed effects ( $F$-test) and random effects (Wald $Z$ ) were carried out at a significance level of $\alpha=0.05$. The $F$-test for fixed effects was partial, i.e. considering the specific contribution of the given effect in addition to all other factors.

\section{RESULTS}

At 3 of the 5 sites, the T-PODs recorded data for the entire period (15 April to 8 November). The 2 remaining sites (Control $\mathrm{N}$ and Control $\mathrm{S}$ ) had periods of missing data due to datalogger failures (Fig. 2). The T-POD data contained 8637 porpoise acoustic encounters with most recorded at Control $\mathrm{N}$ (n = 2628) and Control $\mathrm{S}(\mathrm{n}=1682)$, and fewer encounters recorded at Control E, Impact NW, NE, SW and SE ( $\mathrm{n}=861,742,1034,552$ and 1138, respectively). Data collected during the $2 \mathrm{~h}$ servicing of the instruments were excluded from the analyses, to remove any effects caused by the presence of the service boat. The encounter rates at Control S, Impact NW, NE,

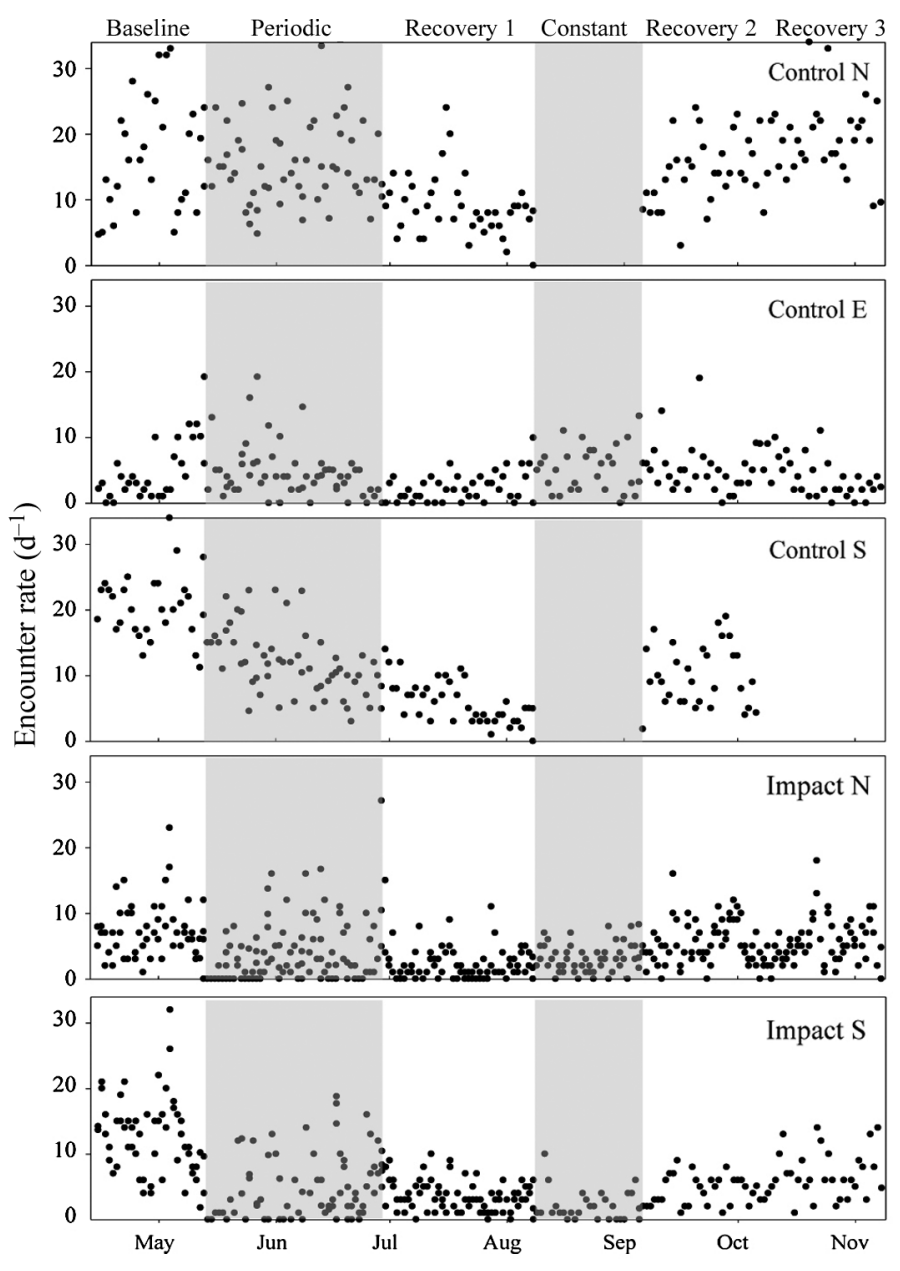

Fig. 2. Daily number of porpoise encounters for each of the 5 areas (Control N, E, S; Impact N, S). Grey columns denote the periods of the Periodic (left) and Constant (right) pinger exposure (all 5 periods of the experiment schedule are indicated at the top of the Control $\mathrm{N}$ panel). Each impact plot presents data from the corresponding 2 impact T-PODs. Periods without observations (Control $\mathrm{N}$ and $\mathrm{S}$ ) indicate gaps in data collection 
Table 1. Pearson's correlations between stations for the log-transformed number of encounters per day during the Baseline period ( $n=29$ d). Significant correlations $(p<0.05)$ are shown in bold

\begin{tabular}{|lcccccr|}
\hline & $\begin{array}{c}\text { Impact } \\
\text { NE }\end{array}$ & $\begin{array}{c}\text { Impact } \\
\text { NW }\end{array}$ & $\begin{array}{c}\text { Control } \\
\text { E }\end{array}$ & $\begin{array}{c}\text { Impact } \\
\text { SE }\end{array}$ & $\begin{array}{c}\text { Impact } \\
\text { SW }\end{array}$ & $\begin{array}{c}\text { Control } \\
\text { S }\end{array}$ \\
\hline Control N & 0.15 & $\mathbf{0 . 5 8}$ & -0.02 & 0.12 & 0.11 & 0.03 \\
Impact NE & & 0.26 & -0.03 & $\mathbf{0 . 4 3}$ & $\mathbf{0 . 4 1}$ & $\mathbf{0 . 3 9}$ \\
Impact NW & & & 0.06 & $\mathbf{0 . 4 7}$ & $\mathbf{0 . 6 0}$ & $\mathbf{0 . 3 9}$ \\
Control E & & & & -0.19 & 0.02 & -0.18 \\
Impact SE & & & & & $\mathbf{0 . 5 6}$ & $\mathbf{0 . 6 2}$ \\
Impact SW & & & & & & $\mathbf{0 . 5 1}$ \\
\hline
\end{tabular}

SW and SE were significantly correlated on a daily basis during the Baseline period (Table 1).

\section{General BACI effect of pingers}

Many of the random effects in the full model (Eq. 1) were not significant and were consequently pooled with the residual variation. Hereafter, 3 random effects were significant (period $\times$ date: $\sigma^{2}{ }_{D P}=0.022, p=$ 0.0270; area $\times$ date: $\sigma_{\text {DA }}^{2}=0.029, p=0.0227$; period $\times$ subarea(area) $\times$ date: $\sigma_{\text {DPS }}^{2}=0.052, p=0.0030$ ) albeit the variance contribution of these effects was small relative to the residual variation $\left(\sigma^{2}=0.301\right)$. The fixed factors in the BACI analysis (Eq. 1) were all significant (Table 2). Over the entire study period and taking the loss of data into account, there were ca. 2fold more encounters in the control area than in the impact area, and within the control subareas Control $\mathrm{N}$ had the most encounters (mean [95\% confidence interval] $\left.14.6 \mathrm{~d}^{-1}[13.1 ; 16.2]\right)$ followed by Control $\mathrm{S}$ $\left(11.3 \mathrm{~d}^{-1}[10.0 ; 12.8]\right)$ and Control E $\left(3.4 \mathrm{~d}^{-1}[3.1 ; 3.8]\right)$. In the impact area the mean encounter rates at Impact $\mathrm{N}\left(3.4 \mathrm{~d}^{-1}[3.1 ; 3.7]\right)$ and Impact $\mathrm{S}\left(4.2 \mathrm{~d}^{-1}[3.8\right.$; $4.7])$ were different $(p=0.0526)$, albeit not significantly. For the control and impact areas combined the encounter rate decreased from the Baseline $\left(9.7 \mathrm{~d}^{-1}\right.$ $[8.6 ; 10.9])$ to Periodic exposure $\left(4.9 \mathrm{~d}^{-1}[4.5 ; 5.5]\right)$ to

Table 2. Before-After-Control-Impact (BACI) analysis of general pinger effect using porpoise daily encounter rates ( $\mathrm{n}=1160$ observations). Fixed effects in Eq. (1) were tested by F-test

\begin{tabular}{|lrrc|}
\hline Effect & \multicolumn{1}{c}{ df } & \multicolumn{1}{c|}{$F$} & $\mathrm{p}$ \\
\hline Area $\left(a_{k}\right)$ & 1,206 & 241.44 & $<0.0001$ \\
Subarea $\left(s_{l(k)}\right)$ & 3,528 & 153.50 & $<0.0001$ \\
Period $\left(p_{j}\right)$ & 5,206 & 33.25 & $<0.0001$ \\
Period $\times$ Area $\left(p a_{j k}\right)$ & 5,528 & 14.07 & $<0.0001$ \\
Period $\times$ Subarea(Area) & 12,528 & 4.92 & $<0.0001$ \\
$\quad\left(p S_{j l(k)}\right)$ & & & \\
\hline
\end{tabular}

Recovery $1\left(3.4 \mathrm{~d}^{-1}[3.0 ; 3.8]\right)$ periods, and then increased from the Constant $\left(5.0 \mathrm{~d}^{-1}\right.$ $[4.1 ; 5.9])$, to Recovery $2\left(6.3 \mathrm{~d}^{-1}[5.6 ; 7.2]\right)$ to Recovery $3\left(7.1 \mathrm{~d}^{-1}[6.2 ; 8.2]\right)$ periods.

The significance of area $\times$ period $\left(p a_{j k}\right.$, Table 2) was a combination of significant and non-significant relative changes between the impact and control areas over time (Table 3, Fig. 3). There was a larger decrease in encounter rate in the impact areas from the Baseline to the 2 Exposure periods (Periodic exposure, Constant; $\sim 60 \%$ ) than from the Baseline to the 3 Recovery periods $(\sim 30 \%)$. There were no significant differences between the 2 exposure periods or between the 3 recovery periods, but there was a significant partial recovery from the 2 Exposure periods to the 3 Recovery periods (Table 3 ). These relative changes were also significantly different for subareas within the control and impact areas (Table 2). Impact $\mathrm{S}$ had a relatively large decrease in encounter rate from the Baseline to the $1^{\text {st }}$ and $2^{\text {nd }}$ Exposure periods. Changes were smaller and of similar size from the Baseline to the Recovery 1 and Recovery 2 periods (Table 4, Fig. 3). The decrease in encounter rate at Impact $\mathrm{S}$ from the Baseline to the Constant exposure period was more than double the decrease from the Baseline to the Periodic exposure at Impact $\mathrm{N}$. In fact, the relative difference between Impact $\mathrm{N}$ and $\mathrm{S}$ was maintained from the Constant exposure to the Recovery 2 periods.

We also examined if Control E, which was located between the 2 impact areas, deviated from the 2 outer control subareas. Relative to Control $\mathrm{N}$ and $\mathrm{S}$, Control $\mathrm{E}$ had an increasing encounter rate from the Baseline to the Periodic exposure periods $\left(F_{2,528}=\right.$ $5.54, \mathrm{p}=0.0042)$, from Baseline to Recovery $1\left(F_{2,528}=\right.$ $7.43, \mathrm{p}=0.0007)$ and from Baseline to Recovery 2 $\left(F_{2,528}=9.12, \mathrm{p}=0.0001\right)$, whereas there were no significant changes between Control $\mathrm{E}$ and Control $\mathrm{N}$ from Baseline to Recovery $3\left(F_{1,528}=1.96, \mathrm{p}=0.1621\right)$. No significant shifts occurred between Control $\mathrm{E}$ and the 2 other control sites from the Periodic exposure to Recovery 2 periods, but there was a significant increase in encounters at Control $\mathrm{N}$ relative to Control $\mathrm{E}$ from the Recovery 2 to the Recovery 3 periods $\left(F_{1,528}=6.52, \mathrm{p}=0.0110\right)$.

\section{Periodic exposure trial}

All the random effects in Eq. (2) were non-significant except for date $\times$ pinger status $\left(\sigma_{\text {DO }}^{2}=0.043, \mathrm{p}=\right.$ $0.0008)$ and date $\times$ subarea(area) $\left(\sigma^{2}{ }_{D S}=0.041, p=\right.$ 
Table 3. Contrasts and their standard error (SE) for relative changes between the control and impact areas for 2 selected periods (First period versus Second period; for definition of periods see 'Materials and methods: Experimental setup') calculated from Eq. (1) estimates $(\log (X+1)$-transformed). The significance of the contrast was estimated by means of a $t$-test, and the relative change and its $95 \%$ confidence interval (in brackets) were calculated as the exponential of the estimate and upper/lower confidence limits minus 1 in accordance with Carstensen et al. (2006). Significant contrasts $(p<0.05)$ are shown in bold

\begin{tabular}{|c|c|c|c|c|c|c|}
\hline \multicolumn{2}{|c|}{$1^{\text {st }}$ period vs. $2^{\text {nd }}$ period } & \multirow{2}{*}{$\begin{array}{l}\text { Estimate } \\
\mathbf{- 0 . 8 2 5 1}\end{array}$} & \multirow{2}{*}{$\begin{array}{c}\text { SE } \\
\mathbf{0 . 1 2 3 3}\end{array}$} & \multirow{2}{*}{$\begin{array}{c}\mathrm{p} \\
<\mathbf{0 . 0 0 0 1}\end{array}$} & \multicolumn{2}{|c|}{ Rel. change (\%) } \\
\hline Baseline & Periodic & & & & -56 & {$[-66 ;-44]$} \\
\hline Baseline & Recovery 1 & -0.3361 & 0.1280 & 0.0098 & -29 & {$[-44 ;-8]$} \\
\hline Baseline & Constant & -1.0379 & 0.1746 & $<0.0001$ & -65 & {$[-75 ;-50]$} \\
\hline Baseline & Recovery 2 & -0.3720 & 0.1400 & 0.0081 & -31 & {$[-48 ;-9]$} \\
\hline Baseline & Recovery 3 & -0.3356 & 0.1464 & 0.0223 & -29 & {$[-46 ;-5]$} \\
\hline Periodic & Recovery 1 & 0.4889 & 0.1113 & $<0.0001$ & 63 & {$[31 ; 103]$} \\
\hline Periodic & Constant & -0.2091 & 0.1625 & 0.1985 & -19 & {$[-41 ; 12]$} \\
\hline Periodic & Recovery 2 & 0.4530 & 0.1251 & 0.0003 & 57 & {$[23 ; 101]$} \\
\hline Periodic & Recovery 3 & 0.4932 & 0.1317 & 0.0002 & 64 & {$[26 ; 112]$} \\
\hline Recovery 1 & Constant & -0.7039 & 0.1660 & $<0.0001$ & -51 & {$[-64 ;-31]$} \\
\hline Recovery 1 & Recovery 2 & -0.0359 & 0.1294 & 0.7816 & -4 & {$[-25 ; 24]$} \\
\hline Recovery 1 & Recovery 3 & -0.0015 & 0.1362 & 0.9913 & 0 & {$[-24 ; 30]$} \\
\hline Constant & Recovery 2 & 0.7172 & 0.1744 & $<0.0001$ & 105 & {$[45 ; 189]$} \\
\hline Constant & Recovery 3 & 0.7024 & 0.1778 & $<0.0001$ & 102 & {$[42 ; 186]$} \\
\hline Recovery 2 & Recovery 3 & -0.0149 & 0.1464 & 0.9192 & -1 & {$[-26 ; 31]$} \\
\hline
\end{tabular}

0.8642), whereas there were $54 \%$ fewer encounters in the impact area when the pingers were active $(p<0.0001)$. The decrease in encounter rate was larger at Impact $\mathrm{S}(65 \%, \mathrm{p}<0.0001)$ than at Impact $\mathrm{N}(40 \%, \mathrm{p}<0.0001)$. There was a tendency, but not significant, for the encounter rate to increase during pingeractive periods after the first 2 to 4 Periodic exposures (Fig. 4).

During the first 2 Periodic exposures the impact areas only had ca. $20 \%$ of the Baseline porpoise encounter rate relative to the control areas. During the $3^{\text {rd }}-5^{\text {th }}$ Periodic exposures, the encounter rate increased to about $35 \%$ of the Baseline rate and during the $6^{\text {th }}$ Periodic exposure it increased to $57 \%$ of Baseline level (Table 6).

At Impact $\mathrm{N}$ there was a significant increase in encounter rate from the $2^{\text {nd }}$ to the $3^{\text {rd }}$ Periodic exposure $(p=0.0027)$, whereas the largest increase at Impact $\mathrm{S}$ occurred after the $4^{\text {th }}$ Periodic expo-

0.0122), although the variance contribution from these random effects was ca. 1 order of magnitude smaller than the residual variation $\left(\sigma^{2}=0.315\right)$. All the fixed effects were significant (Table 5). In the control area there was no significant difference in the encounter rate whether the pingers were active or not (Fig. $4 ; \mathrm{p}=$
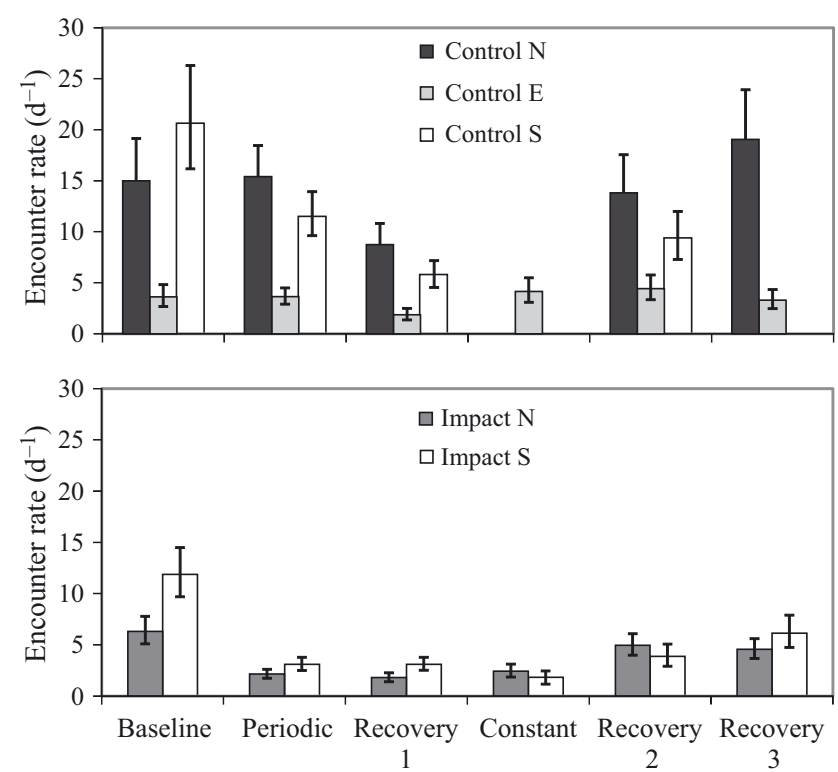

Fig. 3. Estimated marginal mean porpoise encounter rates of the control areas (upper panel) and impact areas (lower panel) for each of the experiment periods, based on backtransformed means. Error bars are 95\% confidence limits sure, although not significant (Fig. 4). There was also a tendency for the intermediate periods between Periodic exposures to have lower encounter rates, but only the periods following the $1^{\text {st }}$ and $2^{\text {nd }}$ Periodic exposures had a significant decline ( 35-40\%) from the Baseline levels relative to trends of the control area (Table 6).

\section{DISCUSSION}

\section{Effect of pinger type}

Both pinger types had a significant negative effect on the number of acoustic porpoise encounters. The encounter decrease was larger for the SaveWave pingers $(65 \%)$ than the Airmar pingers $(40 \%)$. The difference in deterrence effect is likely explained by the higher source level, more variable sounds and higher frequencies of the SaveWave pingers. Porpoises have significantly better hearing in the range in which the SaveWave pingers operate, i.e. 50$150 \mathrm{kHz}$ (50\% detection threshold of 46-72 dB re $1 \mu \mathrm{Pa}$ (rms); best hearing at $100 \mathrm{kHz}$ with $44 \mathrm{~dB}$ threshold). At the $10 \mathrm{kHz}$ frequency at which Airmar pingers operate, porpoise hearing is not as good, even though multiple harmonics may go up into the most sensitive part of the porpoises' hearing range (50\% detection threshold of $62 \mathrm{~dB}$ re $1 \mu \mathrm{Pa}$ (rms) at 
Table 4. Contrasts and their standard error (SE) for relative changes between the Impact $\mathrm{N}$ and Impact $\mathrm{S}$ areas for 2 selected periods (First period versus Second period; for definition of periods see 'Materials and methods: Experimental setup') calculated from Eq. (1) estimates $(\log (X+1)$-transformed). The significance of the contrast was estimated by means of a $t$-test and the relative change and its $95 \%$ confidence interval (in brackets) were calculated as the exponential of the estimate and upper/lower confidence limits minus 1 in accordance with Carstensen et al. (2006). Significant contrasts $(\mathrm{p}<0.05)$ are shown in bold

\begin{tabular}{|c|c|c|c|c|c|c|}
\hline \multicolumn{2}{|c|}{$1^{\text {st }}$ period vs. $2^{\text {nd }}$ period } & \multirow{2}{*}{$\begin{array}{l}\text { Estimate } \\
\mathbf{- 0 . 3 0 4 4}\end{array}$} & \multirow{2}{*}{$\begin{array}{c}\mathrm{SE} \\
\mathbf{0 . 1 5 2 5}\end{array}$} & \multirow{2}{*}{$\begin{array}{c}\mathrm{p} \\
\mathbf{0 . 0 4 6 3}\end{array}$} & \multicolumn{2}{|c|}{ Rel. change (\%) } \\
\hline Baseline & Periodic & & & & -26 & {$[-45 ; 0]$} \\
\hline Baseline & Recovery 1 & -0.1827 & 0.1551 & 0.2395 & -17 & {$[-39 ; 13]$} \\
\hline Baseline & Constant & -0.7866 & 0.1828 & $<0.0001$ & -54 & {$[-68 ;-35]$} \\
\hline Baseline & Recovery 2 & -0.7661 & 0.1778 & $<0.0001$ & -54 & {$[-67 ;-34]$} \\
\hline Baseline & Recovery 3 & -0.3118 & 0.1763 & 0.0775 & -27 & {$[-48 ; 4]$} \\
\hline Periodic & Recovery 1 & 0.1218 & 0.1379 & 0.3777 & 13 & {$[-14 ; 48]$} \\
\hline Periodic & Constant & -0.4821 & 0.1684 & 0.0044 & -38 & {$[-56 ;-14]$} \\
\hline Periodic & Recovery 2 & -0.4616 & 0.1630 & 0.0048 & -37 & {$[-54 ;-13]$} \\
\hline Periodic & Recovery 3 & -0.0073 & 0.1613 & 0.9638 & -1 & {$[-28 ; 36]$} \\
\hline Recovery 1 & Constant & -0.6039 & 0.1709 & 0.0004 & -45 & {$[-61 ;-24]$} \\
\hline Recovery 1 & Recovery 2 & -0.5834 & 0.1655 & 0.0005 & -44 & {$[-60 ;-23]$} \\
\hline Recovery 1 & Recovery 3 & -0.1291 & 0.1639 & 0.4311 & -12 & {$[-36 ; 21]$} \\
\hline Constant & Recovery 2 & 0.0205 & 0.1916 & 0.9148 & 2 & {$[-30 ; 49]$} \\
\hline Constant & Recovery 3 & 0.4748 & 0.1903 & 0.0129 & 61 & {$[11 ; 134]$} \\
\hline Recovery 2 & Recovery 3 & 0.4543 & 0.1855 & 0.0146 & 58 & {$[9 ; 127]$} \\
\hline
\end{tabular}

$8 \mathrm{kHz}$ ) (Kastelein et al. 2002, 2010). Combined with the almost $20 \mathrm{~dB}$ lower ambient noise level at higher frequencies (Fig. 5), porpoises likely can hear the SaveWave signals over significantly greater distances than the Airmar signals. The signal to noise ratio (third octave band level) reached $0 \mathrm{~dB}$ at about $800 \mathrm{~m}$ for the Airmar signal, whereas for the SaveWave signals it was still about $10 \mathrm{~dB}$ at $1600 \mathrm{~m}$. This also suggests that porpoises could hear both pingers long before the T-PODs were able to detect porpoise clicks.

In their review of pingers, Dawson et al. (2013) discussed the 4 hypotheses on how pingers work: (1) The sounds of acoustic pingers are generally aver-

Table 5. BACI analysis of periodic pinger exposure using porpoise daily encounter rates ( $\mathrm{n}=854$ observations). Fixed effects in Eq. (2) were tested by F-test

\begin{tabular}{|lrrc|}
\hline Effect & df & \multicolumn{1}{c|}{$F$} & $\mathrm{p}$ \\
\hline Pinger status $\left(o_{j}\right)$ & 1,115 & 21.30 & $<0.0001$ \\
Period $\left(p_{k(j)}\right)$ & 11,214 & 12.92 & $<0.0001$ \\
Area $\left(a_{l}\right)$ & 1,460 & 239.93 & $<0.0001$ \\
Area $\times$ Pinger status $\left(\right.$ oa $\left._{j l}\right)$ & 1,214 & 46.00 & $<0.0001$ \\
Area $\times$ Period & 11,214 & 4.55 & $<0.0001$ \\
$\quad$ Pinger status) $\left(p a_{k l(j)}\right)$ & & & \\
Subarea(Area) $\left(s_{m(I)}\right)$ & 3,460 & 53.25 & $<0.0001$ \\
Subarea $\times$ Pinger & 3,214 & 3.47 & 0.0171 \\
$\quad$ status $($ Area $)\left(o s_{j m(I)}\right)$ & & & \\
Subarea $\times$ Period status & 33,214 & 2.18 & 0.0005 \\
$\quad$ Area) $\left(p s_{k m(j I)}\right)$ & & & \\
\hline
\end{tabular}

sive and act to displace animals from the vicinity of the pinger; (2) pinger sounds encourage echolocation or otherwise alert the animals to the presence of the net; $_{i}(3)$ pinger sounds interfere with the animals' sonar, causing them to leave the area; and (4) pinger sounds act by altering the distribution of prey (Dawson 1994, Kraus 1999, IWC 2000). Dawson et al. (2013) concluded that the most likely explanation, based on all available studies, is that pingers work by deterrence, i.e. scaring porpoises away. However, a few studies also noted that the vocalization rate initially dropped after pingers were introduced, but increased again later (Cox et al. 2001, Carlstrøm et al. 2009); however, the authors could not conclude whether it was because the porpoises reduced their echolocation rate or because they were displaced too far from the T-PODs to be detected. Teilmann et al. (2006) found an initial drop in echolocation rate when 2 captive porpoises were exposed to pinger-like signals of 1 pulse $4 \mathrm{~s}^{-1}$ in 5 min trials. The response, however, waned rapidly and was only present in 3 out of 25 sessions, which was interpreted as habituation to the signals. As also suggested by Cox et al. (2001) and Carlstrøm et al. (2009), the acoustic encounter rate in our study could have dropped as a result of a decreased echolocation rate, rather than due to the porpoises being deterred, or as a combination of both. Nevertheless, some porpoises were acoustically detected in both impact areas during all periods with active pingers. Since we observed a rather gradual increase in acoustic encounters over days and weeks during the Periodic exposures (Fig. 4), the results of this study lend weight to the most parsimonious explanation, the deterrence hypothesis, rather than to the porpoises remaining silent in the area for several days followed by a gradual increase in echolocation rate.

\section{Gradual lessening of response to pinger signals}

For the 2 impact areas combined, a strong aversive response was observed during the $1^{\text {st }}$ and $2^{\text {nd }}$ Periodic exposure (the acoustic encounter rate decreased to $\sim 20 \%$ of the Baseline level). From there on, the response varied between the 2 impact sites. During the $3^{\text {rd }}$ to the $6^{\text {th }}$ Periodic exposure at the Airmar site (Impact $\mathrm{N}$ ) the response waned and the acoustic 

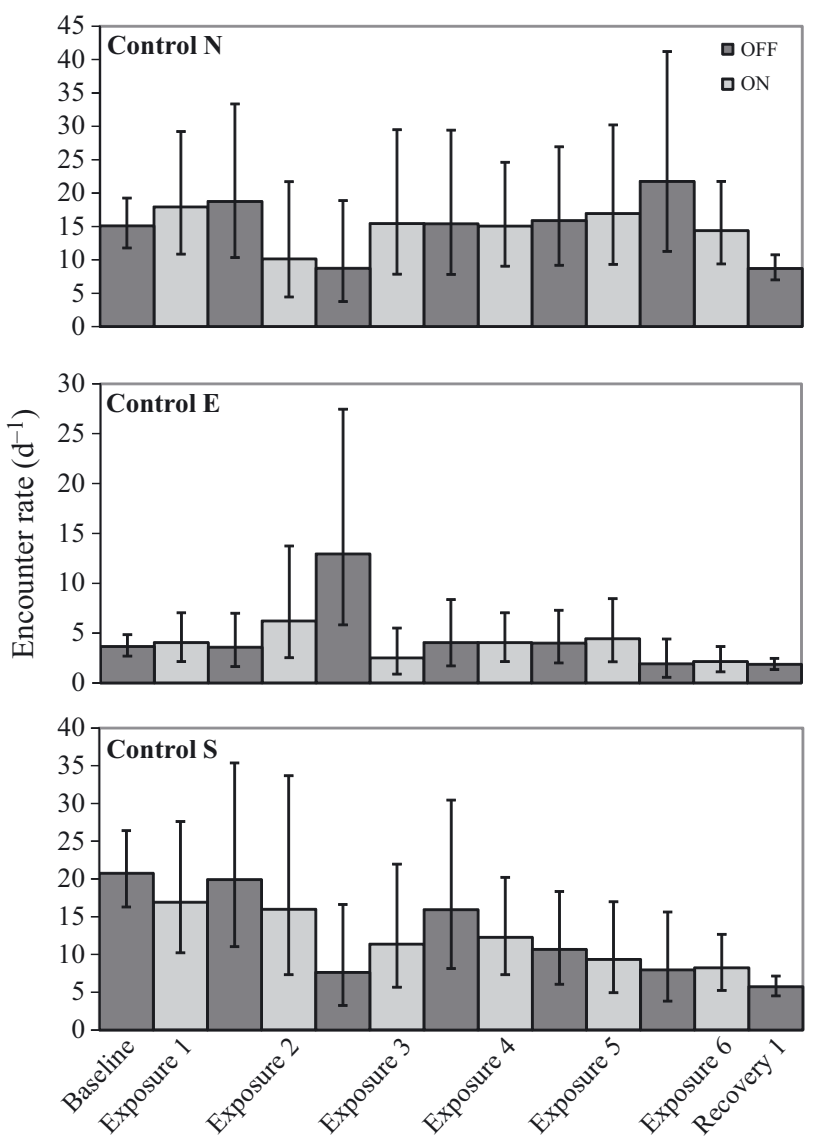

encounter rate seemed to stabilise at about $35 \%$ of the Baseline level. At the SaveWave site (Impact S) the effect lasted to the $5^{\text {th }}$ and $6^{\text {th }}$ Periodic exposure, where there was an increase in acoustic encounters. At both sites the acoustic encounter rate then in-

Table 6. Contrasts and their standard error (SE) for relative changes between the control and impact areas from the Baseline to the 5 intermediate periods between the Periodic exposures ('Second period') calculated from Eq. (2) estimates $(\log (X+1)$-transformed). The significance of the contrast was estimated by means of a $t$-test and the relative change and its [95\% confidence interval] were calculated as the exponential of the estimate and upper/lower confidence limits minus 1 in accordance with Carstensen et al. (2006). Significant contrasts $(p<0.05)$ are shown in bold

\begin{tabular}{|c|c|c|c|c|c|c|}
\hline \multicolumn{2}{|c|}{$1^{\text {st }}$ period vs. $2^{\text {nd }}$ period } & \multirow{2}{*}{$\begin{array}{l}\text { Estimate } \\
\mathbf{- 1 . 6 7 6 4}\end{array}$} & \multirow{2}{*}{$\begin{array}{c}\mathrm{SE} \\
\mathbf{0 . 2 0 9 5}\end{array}$} & \multirow{2}{*}{$\begin{array}{c}\mathrm{p} \\
<\mathbf{0 . 0 0 0 1}\end{array}$} & \multicolumn{2}{|c|}{ Rel. change (\%) } \\
\hline Baseline & 1st exposure & & & & -81 & {$[-88 ;-72]$} \\
\hline Baseline & After 1st exposure & -1.0105 & 0.2424 & $<0.0001$ & -64 & {$[-77 ;-41]$} \\
\hline Baseline & 2nd exposure & -1.5311 & 0.3043 & $<0.0001$ & -78 & {$[-88 ;-61]$} \\
\hline Baseline & After 2nd exposure & -0.8692 & 0.3044 & 0.0047 & -58 & {$[-77 ;-24]$} \\
\hline Baseline & 3rd exposure & -1.0000 & 0.2674 & 0.0002 & -63 & {$[-78 ;-38]$} \\
\hline Baseline & After 3rd exposure & -0.2128 & 0.2673 & 0.4270 & -19 & {$[-52 ; 37]$} \\
\hline Baseline & 4 th exposure & -1.1767 & 0.2102 & $<0.0001$ & -69 & {$[-80 ;-53]$} \\
\hline Baseline & After 4th exposure & -0.0925 & 0.2242 & 0.6805 & -9 & {$[-41 ; 42]$} \\
\hline Baseline & 5th exposure & -1.0373 & 0.2304 & $<0.0001$ & -65 & {$[-77 ;-44]$} \\
\hline Baseline & After 5th exposure & -0.1130 & 0.2480 & 0.6491 & -11 & {$[-45 ; 46]$} \\
\hline Baseline & 6th exposure & -0.5617 & 0.1711 & 0.0012 & -43 & {$[-59 ;-20]$} \\
\hline
\end{tabular}
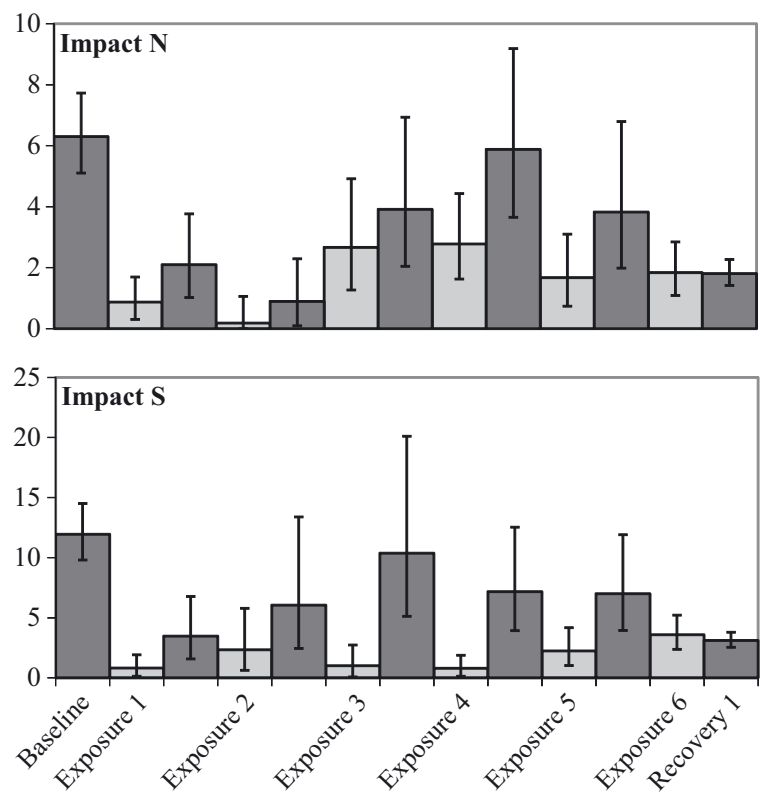

Fig. 4. Estimated marginal mean porpoise encounter rates for the Baseline, Periodic exposures (Exposures 1-6) and Recovery 1 periods, based on back transformed means. Error bars are $95 \%$ confidence limits. Note different $y$-axis scales

creased to $55 \%$ of the baseline level during the $6^{\text {th }}$ Periodic exposure (Fig. 4). It is uncertain whether this would indicate a potential further increase in acoustic encounters over time, had the experiment continued. However, during the period of constant exposure that followed, there was no sign of an increase (Fig. 2). In fact, the acoustic encounter rate was about $35 \%$ of Baseline level throughout the Constant exposure period. That the relative response was about the same during the $3^{\text {rd }}$ to $5^{\text {th }}$ Periodic exposure and during the Constant exposure could indicate that the effect stabilised.

Habituation is measured at an individual level (Thorpe 1966) and the habituation process can be measured as a gradual increase in individual tolerance levels to a stimulus over time (Bejder et al. 2009). We have no information about pinger exposure to the individual porpoises and their responses to the sounds, but we can- 


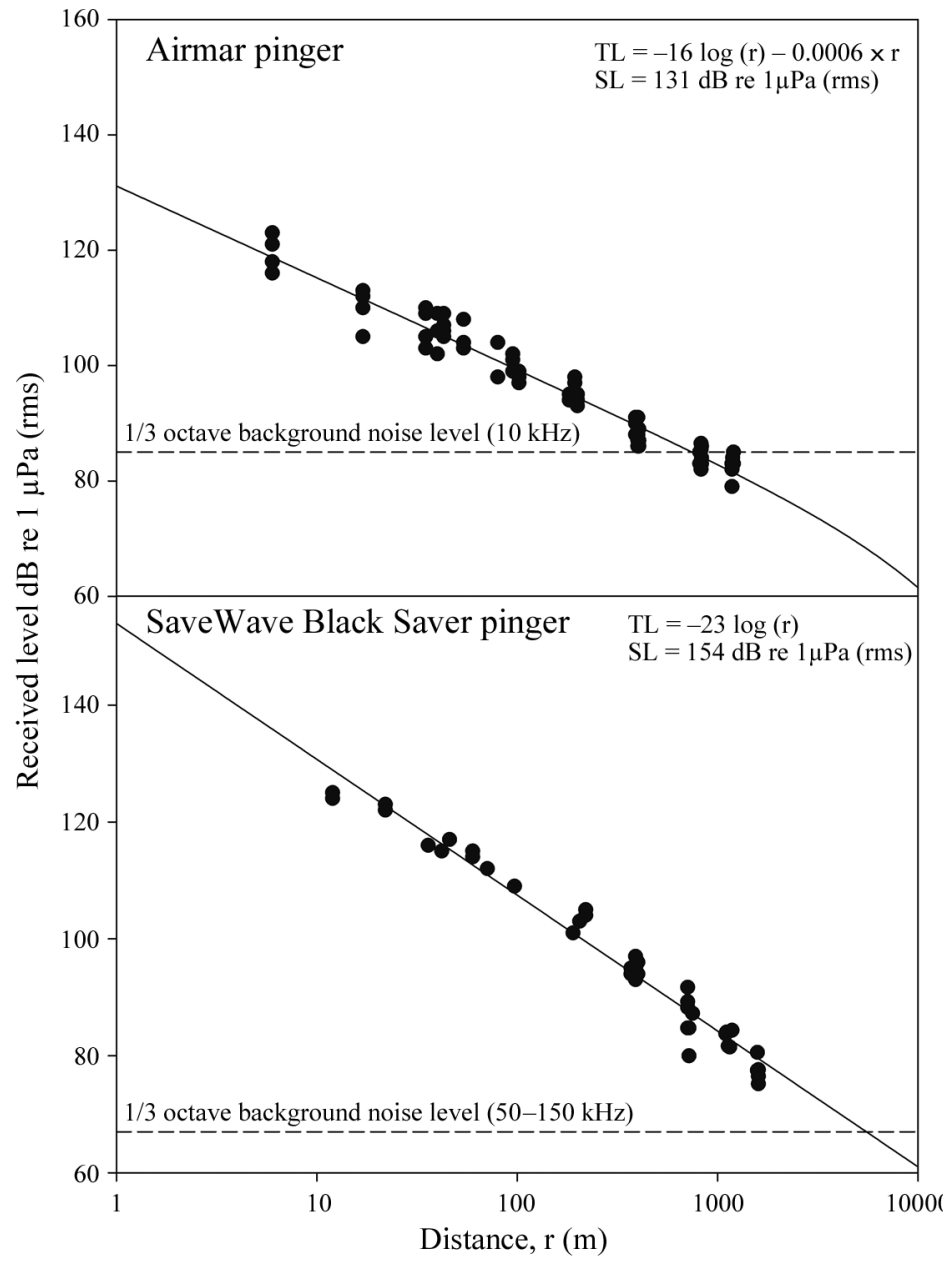

Fig. 5. Received sound levels at various distances (r) from the pingers in the 2 impact areas. Source levels are based on back-calculations. $\mathrm{TL}=$ transmission loss. $\mathrm{SL}=$ source level. The absorption coefficient is not provided in the SaveWave transmission loss formula as absorption is frequency specific and this pinger operates at varying frequencies

not exclude that some individuals were exposed to the sounds several times and that these sounds were not associated with any negative reinforcement. We measured instantaneous changes in acoustic encounters over time, which are suited to the documentation of differing levels of tolerance towards a sound stimulus within a local population of porpoises over time. Here we may therefore interpret the increasing acoustic encounter rate during the Periodic exposures as a gradual habituation at the population level to the pinger sounds, and this may be a sign that habituation took place within some individuals. We expected to observe more habituation during the Constant exposure than during the Periodic exposure. The fact that results showed the opposite could indicate that animals did not move very far away from the experiment sites and therefore quickly returned during periods without pinger sounds (Periodic exposure) or that previously unexposed porpoises migrated through the area and chose to stay during these pinger-free periods.

There are several possible explanations as to why we saw an increase in encounter rate over time in this experiment, but not a full recovery to Baseline levels. First of all it may be that some of the porpoises visiting the study area were travelling through the Great Belt rather than utilising the study site permanently, and therefore left the area to continue their travels when the pinger exposure began. The physiological state of an animal may also influence how well it tolerates disturbances. Hungry turnstones (Arenaria interpres) tolerated a greater level of disturbances than did well fed individuals (Beale \& Monaghan 2004). Phocid seals (Halichoerus grypus and Phoca vitulina) exposed to different aversive sound stimuli in captivity readily habituated to the sound and associated it with food (Götz \& Janik 2010). Thus, the animals were motivated to accept the aversive sound and perhaps both habituated and showed associative learning. On the other hand, Kastelein et al. (2006) in a similar experiment with different types of sound stimuli found that the same 2 seal species did not habituate; however, here the seals were not fed. Harbour seals fled a shorter distance when disturbed by people during the breeding season compared to before and after the breeding season (Andersen et al. 2012). For wild porpoises, for example at our study site, some individuals may tolerate pinger signals better than others due to motivational differences, such as hunger. It may also be that less tolerant porpoises left the area in response to the pingers, resulting in a reduced density of animals, but that a group of porpoises with a more moderate response (Bejder et al. 2009) remained, as acoustic encounters were recorded inside the impact areas even when pingers were active. Nevertheless, the fact that the initial response was a $\sim 80 \%$ reduction in acoustic encounters during the first 2 Periodic exposures over 2 to $3 \mathrm{~d}$, points to most porpoises initially leaving the area.

\section{Habitat displacement}

In this study there was a displacement effect within each pinger test site, whereas no negative effect of pingers was detected in the control areas 2.5, 3 and $5 \mathrm{~km}$ away. It thus seems that the degree of habitat displacement was limited to less than $2.5 \mathrm{~km}$ from the 
pingers. Kindt-Larsen et al. (2011) found a decrease in porpoise presence (vocalizations detected on $\mathrm{T}$ PODs) up to $1600 \mathrm{~m}$ from an active pinger, the maximum distance used in that study. The fact that we did not measure a decrease in acoustic encounters at Control E (between the pinger impact areas) during pinger active trials could indicate that porpoises are not displaced from areas between fishing gears deployed with pingers if the intermediate distance is on the order of a few kilometres. On the other hand, one would expect to see an increase in acoustic porpoise encounters in the 3 control sites during the active pinger trials, if the porpoises were not deterred very far away. That this was not the case means that porpoises either were displaced to areas between the pinger and control areas or that they may have been displaced further away than the immediately surrounding habitats, i.e. $>5 \mathrm{~km}$. It may also be that they did not find these immediate habitats to be as suitable as the habitat they were deterred from. Pingers may therefore affect a larger area than the unaffected controls in this study suggest. If fisheries routinely move their nets around within a larger area, it may affect the porpoise density in the entire area if the animals do not move back once the nets have been moved, or it may affect the distribution of porpoises as they may be forced to relocate every few days.

It may be important to discover which sub-group of a population is leaving an area where pingers are used and whether the individual reaction is context specific. Goldbogen et al. (2013) found that blue whale reactions to mid-frequency sonar signals depended on if, and where, the whales were foraging at the time of exposure. If porpoise mother-calf pairs react more cautiously to a potential hazard (i.e. pinger sounds), they may be excluded permanently from an area. Extensive use of pingers could thus have significant consequences for the population if they are used in important harbour porpoise habitats (for example, Special Areas of Conservation), which has been suggested previously (e.g. Culik et al. 2001, Carlstrøm et al. 2002).

In order to limit the pinger exposure to only those porpoises in danger of entanglement, the pinger source level and pinger spacing on nets should thus be adjusted so that pingers are only effective within close range of the nets (a few hundred meters or less), instead of potentially more than a thousand meters. It has been suggested that porpoises may be capable of detecting fishing nets at distances of up to $80 \mathrm{~m}$ (Nielsen et al. 2012; but see Dawson \& Lusseau 2013, Nielsen et al. 2013). If porpoises are able to detect gillnets up to $80 \mathrm{~m}$ away, it may only be relevant to alert them to a net within this range if they are preoccupied e.g. by foraging. A reduction in pinger detection range is especially important if gillnet fisheries are to take place inside Special Areas of Conservation where noise from pingers may compromise the favourable conservation status for a strictly protected Annex IV species, like the porpoise (EU Habitats Directive, http://ec.europa.eu/environment/nature/ legislation/habitatsdirective/index_en.htm). Such a pinger could be achieved by using high frequency sweep signals of low source level and sufficiently low duty cycle. Development of such a low source level pinger should be tested directly in a fishery with high bycatch rates, as experimental set-ups without nets do not seem to fairly represent harbour-porpoise decision-making at the time that it counts. Also, experiments with wild porpoises carrying tags recording both sound and 3D movements may show how animals react to different pinger types, if the tagged porpoises are released close to, or by chance found near, active pingers.

\section{Lasting effect}

Although to some degree porpoises returned in the 'quiet' periods between the Periodic exposures, the acoustic encounter rate was below expected levels compared to the controls. It cannot be determined whether this was due to a lasting effect of the pinger sound, a confounding effect of the pinger buoys (which were deployed from the $1^{\text {st }}$ Periodic exposure till the end of the $3^{\text {rd }}$ Recovery period), or that the intermediate recovery periods were too short to enable full recovery. Thus, the reduced acoustic encounter rate could reflect a reluctance of the porpoises to re-enter the impact areas when the pinger flags were deployed. However, Carlstrøm et al. (2009) also found that the time to the first acoustic encounter following a pinger trial was significantly longer than when following a control period. This could also explain the fact that even after 2 mo recovery the encounter rate stayed $30 \%$ below the Baseline period (in which no buoys were deployed). Porpoises have been shown to use the study area year-round, although predominantly from March to December and peaking from May to December (Sveegaard 2011).

\section{CONCLUSIONS}

Both SaveWave and Airmar pingers effectively reduced harbour porpoise presence measured as 
acoustic encounters during both the Periodic exposure experiment (mimicking a real fishery) and during the Constant exposure experiment. The number of acoustic encounters increased during the Periodic exposure to Airmar signals, but very little during exposure to SaveWave signals, illustrating a gradual toleration of the Airmar signals over time, which may be caused by habituation of individual porpoises. The reason for the difference in response between the 2 pingers is likely that the Airmar signals were of constant repetition rate, duration and frequency, whereas the SaveWave signals varied in signal type, frequency, duration and repetition rate and were more audible to harbour porpoises. There was, however, no difference in toleration between the pinger types during the Constant exposure experiment. Exposure to the pingers led to a habitat displacement around each pinger site; however, it appeared that displaced porpoises either moved beyond the control sites (i.e. potentially $>5 \mathrm{~km}$ ) or they remained at distances closer than the control sites, i.e. within $2.5 \mathrm{~km}$ of the pinger areas. We suggest that future research should focus on developing a low source level pinger that is audible only within close range of a net in order to reduce the accompanying noise pollution and habitat loss.

Acknowledgements. The study was funded by the Danish Forest and Nature Agency, and the Aage V. Jensen Foundations. Airmar Technology Corporation and SaveWave are thanked for sponsoring pingers. The Danish Society for Nature Conservation, WWF Denmark, the Danish Animal Welfare Society and the Danish Fishermen's Association are thanked for support during the application phase. We thank S. Sveegaard, R. Gregersen, H. Nygaard and J. Stubkjær for their help in the field. M. Jespersen is thanked for GIS-assistance. We also thank the 3 anonymous reviewers for their helpful and constructive comments.

\section{LITERATURE CITED}

Andersen SM, Teilmann J, Dietz R, Schmidt NM, Miller LA (2012) Behavioural responses of harbour seals to humaninduced disturbances. Aquat Conserv Mar Freshw Ecosyst 22:113-121

Beale C, Monaghan P (2004) Behavioural responses to human disturbance: a matter of choice? Anim Behav 68: 1065-1069

Bejder L, Samuels A, Whitehead H, Finn H, Allen S (2009) Impact assessment research: use and misuse of habituation, sensitisation and tolerance in describing wildlife responses to anthropogenic stimuli. Mar Ecol Prog Ser 395:177-185

Carlstrøm J (2005) Diel variation in echolocation behaviour of wild harbour porpoises. Mar Mamm Sci 21:1-12

Carlstrøm J, Berggren P, Dinntz F, Börjesson P (2002) A field experiment using acoustic alarms (pingers) to harbour porpoise by-catch in bottom-set gillnets. ICES J Mar Sci 59:816-824

Carlstrøm J, Berggren P, Tregenza NJ (2009) Spatial and temporal impact of pingers on porpoises. Can J Fish Aquat Sci 66:72-82

Carstensen J, Henriksen OD, Teilmann J (2006) Impacts of offshore wind farm construction on harbour porpoises: acoustic monitoring of echolocation activity using porpoise detectors (T-PODs). Mar Ecol Prog Ser 321: 295-308

Cox T, Read A, Solow A, Tregenza N (2001) Will harbour porpoises (Phocoena phocoena) habituate to pingers? J Cetacean Res Manag 3:81-86

Culik B, Koschinski S, Tregenza N, Ellis G (2001) Reactions of harbor porpoises Phocoena phocoena and herring Clupea harengus to acoustic alarms. Mar Ecol Prog Ser 211: 255-260

Dawson SM (1994) The potential for reducing entanglement of dolphins and porpoises with acoustic modifications to gillnets. Rep Int Whal Comm 15(Spec Issue):573-578

Dawson S, Lusseau D (2013) Pseudo-replication confounds the assessment of long-distance detection of gillnets by porpoises: Comment on Nielsen et al. (2012). Mar Ecol Prog Ser 478:301-302

> Dawson S, Northridge S, Waples D, Read AJ (2013) To ping or not to ping: the use of active acoustic devices in mitigating interactions between small cetaceans and gillnet fisheries. Endang Species Res 19:201-221

EU (European Union) (2004) Council Regulation (EC) No 812/2004 of 26 April 2004 laying down measures concerning incidental catches of cetaceans in fisheries and amending Regulation (EC) No 88/98. OJ L150/12, http://eur-lex.europa.eu/LexUriServ/LexUriServ.do?uri= OJ:L:2004:150:0012:0031:EN:PDF

Goldbogen JA, Southall BL, DeRuiter SL, Calambokidis J and others (2013) Blue whales respond to simulated midfrequency military sonar. Proc R Soc Lond B Biol Sci 280: 20130657

Götz T, Janik VM (2010) Aversiveness of sounds in phocid seals: psycho-physiological factors, learning processes and motivation. J Exp Biol 213:1536-1548

Green RH (1979) Sampling design and statistical methods for environmental biologists. Wiley, New York, NY

Hardy T, Williams R, Caslake R, Tregenza N (2012) An investigation of acoustic deterrent devices to reduce cetacean bycatch in an inshore set net fishery. J Cetacean Res Manag 12:85-90

IWC (International Whaling Commission) (1994) Report of the workshop on mortality of cetaceans in passive fishing nets and traps. Rep Int Whal Comm Spec Issue 15:6-57

IWC (2000) Report of the scientific committee. Annex I. Report of the sub-committee on small cetaceans. J Cetacean Res Manag 2(Suppl):235-257

Kastelein RA, de Haan D, Vaughan N, Staal C, Schooneman NM (2001) The influence of three acoustic alarms on the behaviour of harbour porpoises (Phocoena phocoena) in a floating pen. Mar Environ Res 52:351-371

Kastelein RA, Bunskoek P, Hagedoorn M, Au WWL, de Haan D (2002) Audiogram of a harbor porpoise (Phocoena phocoena) measured with narrow-band frequencymodulated signals. J Acoust Soc Am 112:334-344

Kastelein RA, van der Heul S, Terhune JM, Verboom MC, Triesscheijn RJV (2006) Deterring effects of 8-45 kHz tone pulses on harbour seals (Phoca vitulina) in a large pool. Mar Environ Res 62:356-373 
Kastelein RA, Hoek L, de Jong CAF, Wensveen PJ (2010) The effect of signal duration on the underwater detection thresholds of a harbor porpoise (Phocoena phocoena) for single frequency-modulated tonal signals between 0.25 and $160 \mathrm{kHz}$. J Acoust Soc Am 128:3211-3222

Kindt-Larsen L, Wahlberg M, Larsen F (2011) Evaluering af marsvins adfærd og habituering i forhold til redskabsselektion med akustiske alarmer. DTU Aqua, Ministry of Food, Agriculture and Fisheries of Denmark, København

Koschinski S, Culik BM, Trippel EA, Ginzkey L (2006) Behavioral reactions of free-ranging harbor porpoises Phocoena phocoena encountering standard nylon and $\mathrm{BaSO}_{4}$ mesh gillnets and warning sound. Mar Ecol Prog Ser 313:285-294

Kraus S (1999) The once and future ping: challenges for the use of acoustic deterrents in fisheries. Mar Technol Soc J 33:90-93

Kraus S, Read A, Solow A, Baldwin K, Spradlin T, Anderson E, Williamson J (1997) Acoustic alarms reduce porpoise mortality. Nature 388:525

Kyhn L, Tougaard J, Teilmann J, Wahlberg M, Jørgensen P, Bech N (2008) Harbour porpoise (Phocoena phocoena) static acoustic monitoring: laboratory detection thresholds of T-PODs are reflected in field sensitivity. J Mar Biol Assoc UK 88:1085-1091

Kyhn LA, Tougaard J, Thomas L, Duve L and others (2012) From echolocation clicks to animal density-acoustic sampling of harbor porpoises with static dataloggers. J Acoust Soc Am 131:550-560

Larsen F, Krog C (2007) Fishery trials with increased pinger spacing. Int Whal Comm Sci Comm Rep 59(SM2):1-8

Larsen F, Vinther M, Krog C (2002) Use of pingers in the Danish North Sea wreck net fishery. Int Whal Comm Sci Comm Rep 54(SM32):1-8

Lien J, Barney W, Todd S, Seton R, Guzzwell J (1992) Effects of adding sound to cod traps on the probability of collisions by humpback whales. In: Thomas J, Kastelein R, Supin E (eds) Marine mammal sensory systems. Plenum Press, New York, NY, p 701-708

Littell R, Milliken G, Stroup W, Wolfinger R (1996) SAS system for mixed models. SAS Institute, Cary, NC

McCullagh P, Nelder J (1989) Generalized linear models, 2nd edn. Chapman \& Hall/CRC, Boca Raton, FL

McCulloch C, Searle S (2001) Generalized, linear, and

Editorial responsibility: Peter Corkeron,

Woods Hole, Massachusetts, USA mixed models. Wiley, New York, NY

Nielsen TP, Wahlberg M, Heikkilä S, Jensen M, Sabinsky P, Dabelsteen T (2012) Swimming patterns of wild harbour porpoises Phocoena phocoena show detection and avoidance of gillnets at very long ranges. Mar Ecol Prog Ser 453:241-248

Nielsen TP, Wahlberg M, Dabelsteen T (2013) Assessment of long-distance detection of gillnets by porpoises: Reply to Dawson \& Lusseau (2013). Mar Ecol Prog Ser 478: 303-305

Northridge S, Sanderson D, Mackay A, Hammond P (2003) Analysis and mitigation of cetacean bycatch in UK fisheries. Final Report to DEFRA, Project MF0726

Palka D, Rossman M, Vanatten A, Orphanides C (2008) Effect of pingers on harbour porpoise (Phocoena phocoena) bycatch in the US Northeast gillnet fishery. J Cetacean Res Manag 10:217-226

Read A (1994) Interactions between cetaceans and gillnet and trap fisheries in the Northwest Atlantic. Rep Int Whal Comm Spec Issue 15:133-147

Shapiro AD, Tougaard J, Jørgensen PB, Kyhn LA and others (2009) Transmission loss patterns from acoustic harassment and deterrent devices do not always follow geometrical spreading predictions. Mar Mamm Sci 25:53-67

Sveegaard S (2011) Spatial and temporal distribution of harbour porpoises in relation to their prey. PhD thesis. Dept. of Arctic Environment, NERI. National Environmental Research Institute, Aarhus University

Teilmann J (2003) Influence of sea state on density estimates of harbour porpoises (Phocoena phocoena). J Cetacean Res Manag 5:85-92

Teilmann J, Tougaard J, Miller L, Kirketerp T, Hansen K, Brando S (2006) Reactions of captive harbor porpoises (Phocoena phocoena) to pinger-like sounds. Mar Mamm Sci 22:240-260

Thorpe W (1966) Learning and instinct in animals. Harvard University Press, Cambridge, MA

Trippel E, Stong M, Terhune J, Conway J (1999) Mitigation of harbour porpoise (Phocoena phocoena) by-catch in the gillnet fishery in the lower Bay of Fundy. Can J Fish Aquat Sci 56:113-123

Vinther M (1999) Bycatches of harbour porpoise (Phocoena phocoena L.) in Danish set-net fisheries. J Cetacean Res Manag 1:123-135

Submitted: January 7, 2014; Accepted: December 29, 2014 Proofs received from author(s): March 30, 2015 